\section{DIGITAL COMMONS \\ @ UNIVERSITY OF SOUTH FLORIDA}

\section{Journal of Practitioner Research}

\title{
Collaborating across National Boundaries for Narrative Teaching and Learning
}

Haji Karim Khan

University of Baltistan, Skardu, hajikarim.khan@gmail.com

Theresa Y. Austin

University of Massachusetts - Amherst, taustin@educ.umass.edu

Follow this and additional works at: https://digitalcommons.usf.edu/jpr

Part of the Adult and Continuing Education and Teaching Commons, and the Higher Education Commons

\section{Recommended Citation}

Khan, Haji Karim and Austin, Theresa Y. (2018) "Collaborating across National Boundaries for Narrative Teaching and Learning," Journal of Practitioner Research: Vol. 3 : Iss. 2 , Article 4.

https://doi.org/10.5038/2379-9951.3.2.1087

Available at: https://digitalcommons.usf.edu/jpr/vol3/iss2/4

This Practitioner Research is brought to you for free and open access by the Open Access Journals at Digital Commons@ University of South Florida. It has been accepted for inclusion in Journal of Practitioner Research by an authorized editor of Digital Commons @ University of South Florida. For more information, please contact digitalcommons@usf.edu. 
Collaborating across National Boundaries for Narrative Teaching and Learning

\section{Cover Page Footnote}

We are grateful to the students with whom we interacted in the course and the four guest lecturers who generously shared their expertise with us. The First Author acknowledges the Fulbright leadership for giving him an incredible opportunity to visit the USA as a Visiting Scholar. 


\begin{abstract}
University faculty members always learn through their collaborative engagement in teaching and research. This article reports on collaborative efforts between a Pakistani and US university professor to develop and teach a graduate seminar on narrative inquiry. We used a self-study approach to record, analyze, and report on our experience of teaching narrative inquiry in a graduate research course. We used our reflective journals, course outline, course description, session plans, class-notes, and students' reflections as data for analysis. As a result, we developed our analytical stories of experiences under several themes.

Findings showcase insights arising from philosophical (ontological and epistemological) underpinnings, moral and ethical boundaries, and instructionrelate challenges. These are interconnected and interdependent issues that can inform narrative educators. Our collaborative and collegial approach was instrumental to facilitate learning in the classroom. The article also highlights certain pertinent implications related to teaching and learning of narrative inquiry.
\end{abstract}

\title{
Introduction
}

What happens when university professors and graduate students explore unfamiliar terrain together? If conditions are set for collaboration, each brings curiosity and creativity to the encounter. As two professors in a graduate education program, we started our joint academic journey mid-October (Fall 2016) preceding offering the seminar. This article reports on our collaboration as two university teachers to develop and implement a 'narrative inquiry' course in a university located in the USA. We both have published narrative inquiries in our respective countries but engage in this dialogic narrative together for the first time. One of us, Khan, hails from Pakistan. He teaches in a public sector university in Pakistan and came to the USA as a visiting faculty. From a sociocultural perspective, he has conducted narrative and life history research with teachers and teacher educators in Pakistan. Likewise, Austin, is a US national who teaches in the host university and who also serves as a mentor to Khan. From a sociolinguistic perspective, she has employed narrative inquiry and analysis in the study of language teacher education and second language and literacy development. Together we pooled our joint resources to provide an apprenticeship for graduate students through our collaborative academic work.

Key to the collaboration between instructors and students was the focus and joint examination of narrative inquiry's ontology, epistemology and axiology for socially transformative research in education. We tell our story with the stories of our students about the entangled paths of discovery, dialog and learning that was made possible. This study contributes a heuristic perspective on narrative inquiry and analysis and adds how collaboration and dialogism can work in researcher development. 


\section{Background}

As narrative inquiry gains ground in educational research, it displaces space and privilege often unquestionably given to experimental studies. Yet in preparing graduate students to become familiar with this epistemology, a clear contrast is needed to not only highlight their differences but to also illustrate contributions and challenges. Within this context, the insights gained from research on lived experience are increasingly significant in education (Connelly, \& Clandinin, 1990). Researchers have identified narrative inquiry as a powerful tool to study lives, events, social contexts, and experiences. Advocating the use of narrative studies in education, Connelly and Clandinin (1990) argue that "the main claim for the use of narrative in educational research is that humans are storytelling organisms who, individually and socially lead storied lives. The study of narrative, therefore, is the study of ways humans experience the world" (p. 2).

Connelly and Clandinin (2006) highlight three key characteristics of narrative inquiry that give it distinction among other methodologies. These characteristics include temporality, sociality, and place. Temporality refers to the notion that events that we study are always in temporal transition. This refers to the past, present and future of people or events under study. Similarly, 'sociality' concentrates on both personal and social conditions. Feelings, desires, and aesthetic preferences are considered as personal conditions. Social conditions are related to the contexts and cultures or social worlds under which individual experiences things and events occur. In addition, the researcher and research participants' relationship is also seen as a form of the social condition. Likewise, the term 'place' refers to the concrete and physical boundaries of place where the study takes place.

Narrative research has made its way to some of the eastern countries as a robust research approach in social sciences and education. Some of the universities gave room to narratives in their graduate courses on research methods. One of us, Khan, has had the firsthand experience of learning and doing narrative research studies in Pakistan, in the South Asian context. Our own experience of learning narrative inquiry played a key role in the course development and instruction. We therefore give account of our learning to conduct narrative inquiries in our respective fields.

\section{$\underline{\text { Khan as a Learner: Unlearning and Relearning }}$}

I came across the term 'narrative inquiry' in a course during my $\mathrm{Ph} . \mathrm{D}$. program. I initially thought "How could stories be considered as research?" Certain questions surfaced in my mind such as: how does one discern if participants are telling the truth? How is it that reality is "constructed"? In other words, what is the "truth" and how it can be constructed? What is the role of the researcher? How can a researcher be unbiased? How can the results/findings be generalizable or replicable? Most of these questions seem to have strong base in the positivist paradigm. This is due in part to the common perceptions about research in my 
country and the global enterprise of educational research. In Pakistan, quantitative survey research is the most commonly used method for inquiry; consequently, the research discourse in the country generally involves concepts such as 'hypothesis', 'null hypothesis', 'validity and reliability', 'truth' 'questionnaire', and 'observation checklist' etc. Having these prior assumptions about research, sitting in a narrative research course without any discussion of the above-mentioned concepts, was something very new and unusual for me. Thus my journey towards making sense of the narrative landscape started from that day.

The limited knowledge and understanding pertaining to narratives as research approach in the larger social and academic context frequently not only created challenges during my conceptualization of this field, but also later during the data collection. Thus, as mentioned by Phoenix (2013) personal narratives (biographic) and local and larger social contexts are interlinked, my story is also nested in the larger context of educational research. When I reflect back on my own learning of narrative inquiry I can categorize my learning in three different, but intertwined phases:

- $\quad$ Shifting paradigm towards interpretive biographic accounts;

- $\quad$ Learning the language of narratives; and

- $\quad$ Developing the understanding.

Understanding the nature of the reality (multiple versus mono) and its construction, and the role of the researcher in the knowledge construction were also the key debates in the struggle to the paradigm shift. My preconceived notions about knowledge (structuralist and positivist perspectives) and its epistemological concerns were the initial obstacles in front of me. I struggled to understand the constructivist notion of knowledge and learning, multiple realities, verisimilitude, (Denzin, 1989), rigor (Cole \& Knowles, 2001) and trustworthiness (Lincoln \& Guba, 1985) among other concepts. I had to revisit my perspectives about knowledge, knowledge development, ways of knowing, and the truth. As a result, I realized a paradigm shift in my thinking about research in general and that of educational research in particular.

I realized the importance of knowing about teachers, their lives, and lived experiences in the context of teaching and learning (Goodson, 2003), which unfortunately, has been a missing element in the educational research agenda in Pakistan. As a result of my deep reflections on narratives and biographical studies, I became an advocate of narrative approach in studying teachers' lives, identities, and practices. I then used life history approach in my Ph.D. thesis in 2009 (Khan, 2009) and subsequent publications (Khan, 2011). The use of narrative approach in studies helped me develop an understanding of the very field of research, which had a very limited purchase in my country's educational research arena.

Working with professor Austin, in the USA in terms of developing and instructing a graduate course in narrative inquiry was a huge learning opportunity for me as a researcher and teacher. The interaction helped me unpack several 
questions related to narratives and to see how this approach is being used in various fields.

\section{Austin's Story:}

The idea of a seminar on narrative inquiry and analysis was appealing to me as I was working with graduate students in leading our concentration's ethnography field research course. Several students had requested a deeper-guided examination of this field beyond the three weeks we had dedicated to it in our ethnographic course. During the same period our college had also created a review of research courses to be identified for the doctoral program. Thus the opportunity was ripe to focus on narrative inquiry from various epistemological standpoints and to look into a variety of settings that could also integrate international perspectives given the presence of Khan, our visiting scholar from Pakistan. My own wonderings about how narrative inquiry could be a valuable asset to our program, led to my discussing this with several colleagues and subsequently to gaining their support for a seminar to enrichen the qualitative research offerings.

My history of working with narrative inquiry started over a decade ago, when I was examined conflicting discursive practices that positioned me in teacher education. A prominent editor of a second language research journal who read my text at that time, gently informed me that narrative inquiry was not research. Thus I was obligated to search for another venue to publish my manuscript. In the following decade the same editor has since published his own narrative inquiry, providing further gratifying evidence that narrative research has not only gained hallowed ground but also powerfully compelled researchers in second language education to explore and analyze teaching and learning from a narrative approach. My curiosity in sorting out for myself difference and similarities between narrative inquiry, self-studies, and auto-ethnographic research spurred my collaboration with our international scholar.

Thus, our joint reflections on how we ourselves learnt, what challenges we faced, and how we overcame those challenges, enabled us to relate them with those of our current students in the course. As a result, we decided to balance the blend of theory and practice in the course through a mentorship that was both dialectic and dialogic. It was an egalitarian interaction based on the data (our reflections, students' work) rather than a hierarchical power relation. Based on our readings and experience, we summarize key distinctive elements of narrative research below:

- A narrative approach is nested in the interpretive paradigm of social science research.

- Narrative inquiry has specific procedures for representing participants' reality, for analysis and confirmation of insights (rigor, verisimilitude, trustworthiness, thick description) 
- Narrative studies are iterative, emergent, and interpretive in nature (Dörnyei, 2007) that make them more robust, flexible as well as prone to the subjective interpretations of the researchers.

- $\quad$ Language plays a key role as a medium to render the essence of experience (Denzin, 1989). Narratives also encourage multiple forms of languages.

- Data (interviews, written documents, oral accounts) are situated in time and place, told by the participants.

- Narrative researchers believe in multiple realities. They advocate that reality is socially constructed. Truth is co-constructed by power relations between individuals and the researchers based on interactions.

- Narrative researchers become, as narrator, also co-constructor and presenter of the story.

Therefore, the above served as premises from which we conducted this narrative inquiry into our apprenticeship for graduate students in the seminar. Our interpretation of these practices is based on our joint involvement in the process, living with the experiences, and interpreting those experiences individually as well as collectively. Thus the relationship between us was a collegial one that enabled us learning through a collaborative inquiry into our practices of teaching narratives.

\section{The Research Process: Storying The Experiences}

We employed a narrative approach to capture our own experience of teaching narrative inquiry in the graduate classroom. As mentioned by Connelly and Clandinin (1990), "because of its focus on the experience and qualities of life and education, narrative is situated in a matrix of qualitative research" (p. 3). We took self-study approach of narrative studies to capture our experience of teaching narrative inquiry in a graduate education program. Self-study research has been seen as an important aspect of teachers' professional development, knowledge construction, and reflecting upon their roles as educators (Bashiruddin, 2006; Loughran, 2005; Schulte, 2005; Zeichner, 2005). We would call it a "shared narrative" to study our experience of teaching of narrative inquiry in a university classroom. We shared our individual experience with each other and came up with a shared story of experience so as to analyze it and make it public for the learning and academic purposes.

Individual and joint reflections on our actions were the key sources of data. From the very beginning to the end, we kept our individual reflective journals so as to record our reflections and share with each other in the meetings. Beside our own reflective journals, the work produced by our students (assignments, presentations) their reflections and anonymous feedback at the end of the semester, were also part of the data. We acted as critical friends to each other so as to share reflections while thinking aloud, giving feedback to each other, and highlighting future course of actions. We conducted focus group and whole class discussions so as to reflect upon the overall course experience. As a result, elicited students' feedback on the course and how they experienced it. We also developed a set of questions asking about the 
course experience and handed over them to individual students to fill anonymously. That also enabled us to get feedback on the course.

We employed a thematic analysis for data analysis (Barkhuizen, Benson, \& Chik, 2014). Our individual reflective journals, class notes, session plans, and students' reflections on the Moodle were key sources of data. We developed themes reading through the data from these sources several times. The rapidity emerging aspects from all the sources of data became the ultimate themes. Development of such themes become key components of the bigger story of teaching narrative inquiry. The bigger story consists of two smaller stories from the planning and instruction phases.

\section{The Story of Planning: The Dilemmas of Content Selection and Power Dynamics}

Our journey started with finding common ground for the course development. Since we both come from two different backgrounds with respect to our work and use of narrative inquiry, it was vital to educate each other about our respective work within our disciplines and come to consensus with respect to decision-making for the course. Therefore, in meetings for developing the course we shared readings from our respective fields and also discussed their potential contributions. This helped us to set shared objectives for the course and select the content and activities. We decided to include content central to our respective interests, language/literacy and teacher education. In doing so, Khan's interest focused on the broader picture of research in teacher education whereas Austin focused on narrative research in language, literacy and culture education. In addition, our collaboration resulted in inclusion of international literature, particularly from the developing country context like, Pakistan. This is in fact an important step to address the very critique on knowledge as western or northern dependent.

As we both come from two different backgrounds, in terms of our academic orientations, cultural contexts, and work experience, we took our differences as strengths. Our discussions and reflections used to involve disagreements too. Our reflections show that the element of power dynamics always remained there. For instance, Khan continuously saw Austin as a mentor and guide. It could be due to his experience in a context, such as Pakistan, where a teacher has always respect and dignity in the society (Malik, 2004). In addition, unlike Austin, in his case, developing a graduate level course in a university in a new context (USA) was totally a new experience for him. Knowing the national, state and the institutional policies, procedures, standards, and demands were indeed huge tasks to be accomplished. Thus, he initially saw himself as 'expert becoming a novice' (Murray, 2005; Khan, 2011). He mentioned in his reflective journal:

The context here [university in the USA is totally a new context for me. The socio-economic and political context is new for me, the cultural norms and values are new, the culture of teaching and learning is new, students are 
from diverse background, policies and procedures are different, overall university milieu is new! Though I have a vast teaching experiences in my country, yet here I feel like a novice! As if I need to learn from the scratch! I feel myself in a situation of unlearning and relearning! Therefore, working with my mentor gives me the opportunity to learn and educate myself about the new context!

Khan counted on Austin as his mentor to inform him about the policies, and procedures in developing and teaching a graduate course in the USA context. Austin expected a more equal relationship as among peers. She had hoped for students to also learn how to disagree with each other as well as with her and Khan. By reducing the hierarchical structure, Austin had hoped to set conditions for all participants to critically interpret, wonder, and analyze each other's texts. Her reflections were indicative of her concern.

Seems like my interactions are much longer than I expected them to be. It really is supposed to be a dialogic seminar. How can I better manage my contributions so that Khan can participate more readily as the co-instructor? I am worried that the students look to me too often to wrap up the final points.

Thus, the dilemma is highlighted of the power dynamics in terms of Khan and the students considering Austin as the final authority and the struggle of her to establish a collegial and supportive learning environment continued almost throughout the course.

\section{Stories from the Classroom: Teachers and Students Becoming Co-Learners and Co-Constructors}

Our instructional practice remained dialogic and inquiry-oriented as we discussed various theories and encouraged students to engage with them through inquiry-based learning. We gave our students opportunities to develop their individual projects, implement them, reflect upon their learning, and share their stories of learning in the course.

Most students preferred the multi-pronged active learning strategies and found that it was helpful in grasping various concepts. For instance, one student reflected on his learning, "reading, discussing it in the classroom, and then implementing a concept in the real life situation always helps in learning the concepts". We took a semi-guided multipronged approach to facilitate our students' learning. For instance, our students developed their individual research questions, tools such as interview guide, consent letters and went through the process of meeting the demands of the Institutional Review Board (IRB) in connection with the ethical considerations of the Social Science research. They presented their tools and methodological approaches in the classroom so as to get feedback from their 
peers and the faculty members. Some extracts from our students' reflections are provided below.

Student X: "I always learn from my fellow students when they present their projects. I also receive feedback on my presentation, which helps to improve my learning".

Student Y: "presenting my work in the class always helps me clarifying the misconceptions".

Student Z: "The feedback on my preliminary findings from faculty and peers were very helpful before submitting the final draft. Likewise, the one-to-one meeting with faculty members is always an opportunity to receive feedback".

We also came across the complexities and challenges of teaching narrative inquiry. Much more guided practice and scaffolding needed in each of the stages. We found that teaching narrative inquiry was not a linear process; rather, it was a process of moving to-and-fro. We realized that classroom practices did not always go as we planned. Our plans often remained ambitious in nature. We faced shortage of time for certain objectives to accomplish. As a result, we came to know that our session plans were dependent on several associated things, such as:

- Learners' prior concepts of reality in narrative inquiry, ways of formation of the reality, and addressing them in their respective research projects;

- Skills of doing analysis of qualitative data using traditional and contemporary computer assisted methods; and

- $\quad$ Learners' prior readings and preparations related to weekly planned themes.

We realized that in some cases we underestimated time required for certain skills such as use of NVivo and the complexity of coding procedures. For instance, we had planned one session on the use of NVivo in narrative analysis. Our reflections showed that one day was not enough. Learning the use of NVivo needed more guided practice so as to make sense of it. Khan's reflection on the session on NVivo shows the complexity of knowing various concepts simultaneously. He reflected:

As emerging researchers our students need to learn not only the traditional or manual approaches of analysis but also the use of contemporary technologically assisted ones. It is important that our students are abreast with the use of technology in the contemporary world. Therefore, inclusion of use of the NVivo in the course was a good decision. However, the placement of the use of NVivo in the course needed a revisit. We introduced it during the time when the students were involved in data analysis phase of their individual projects. Thus, they had to struggle with many things simultaneously. For instance, mastering the analytical skills, and the use of NVivo in data management and analysis. Hence, placing the NVivo earlier in the course would help them to use it comfortably later in their data management and analysis. 
We also realized that our students needed more guided practice in writing memos and narrative reports. We therefore allocated certain time in our session plans for the guided writing practice. However, we could not implement it as such. We always faced time constraints in doing so. It was because of the questions raised by the learners and the time for scaffolding they needed to grasp the concepts and as teachers we privileged our students' learning over following the prescribed session plans.

Some of the students needed additional time during the initial conceptualization of their individual projects, selecting topics, and initiating their fieldwork. Our reflective journals highlighted the dilemma of time constraints. For instance, Khan wrote:

The plan for our today's session seemed to be very ambitious. We had allocated time for the students' individual write-up of their projects but we could not do so. It was because our earlier activities took almost all of the time. The discussion on reporting narrative inquiry and on ethical concerns took a longer time than what we expected. This is the second time we could not give time for the students to practice their writing under the guidance of the faculty. We might have planned much for a limited time.

Thus, we realized that time management remained a key issue during the instructional phase. In some cases, we could not accomplish what we aimed to accomplish. It means that our students needed much more time to grasp various concepts of narrative inquiry and to strengthen certain required skills in carrying our narrative inquiry in their respective projects.

\section{The Objectivity Versus Subjectivity Debate}

Objectivity/subjectivity debate has always been parts of the discourses on interpretive approaches in general and that of narratives in particular. The following were the most commonly raised questions and concerns in the classroom at the earlier stage.

- How can we make sure whether or not the told stories are authentic and reliable?

- The research participants may not tell exactly the same story if asked to retell multiple times and occasions.

- How can a researcher be sure whether or not he/she has captured exactly the same story that was meant by the research participant?

- How does a researcher ensure objective analysis?

- The sample size is generally small in narratives; how can a researcher generalize the findings?

- A researcher may interpret things the way he/she wants to.

All of the above questions and concerns are related to the very notion of reality formation in interpretive studies. This could be due to our students' 
perceptions about research findings. For example, some extracts from the students' reflections are given below.

Student A: "the findings of a research study always need to be valid and reliable."

Student B: "a researcher can interpret things the way he/she wants. Different researchers may interpret the same data differently."

Student C: "My major concern is that how I could decode the data more objectively without the intervention of my personal perception or assumptions".

In the above-mentioned extracts, besides the skepticism about the data interpretation, the terms "valid", "reliable", "decode", "objectively", are some of the terms used in the positivist approach. The prior notions about research and research findings had always become points for discussions in the class. The questions and concerns raised by the course participants were the basic to be addressed in a research course. Thus, the key question for us was how to engage our students in critical discourses and practices so as to make sense of the very concept of narrative inquiry and its complexities. We facilitated our students to raise questions and seek solutions through a collaborative engagement.

With the duration of the course, several of our students struggled with the idea of reality being multiple because of its construction by research participants. There seemed to be an enduring assumption that there exists but one truth, one reality, which was deeply ingrained in these students. This point highlights the pervasiveness of positivist research assumptions that many educational researchers dearly hold onto. However, in becoming familiar with a narrative perspective over time, students could develop an initial understanding of this multiplicity. For example, Student X, in her reflection said, "given the social construction of the reality in narrative studies, it is the researcher's responsibility to describe in detail how the data were gathered, analyzed and interpreted, as well as clearly state the limitations of the study". This was indeed a very powerful reflection showcasing her learning in terms of how to maintain trustworthiness in a narrative study.

\section{Defining the Ethical Complexities}

Ethical considerations in narrative inquiries were one of the important components of our course. Our students raised certain pertinent questions related to research ethics. For instance, one of the students also raised some robust questions in her reflective writing. She wrote,

An ongoing question for me is when and where to gain informed consent? Is it better to build relationship with prospective participants before asking for consent? Or is it better to introduce consent at the early stages of the research process? How do we as researchers approach the process of gaining informed consent? How do we explain it to gatekeepers? 
Thus the ethics related concern raised by the student show her engagement in thinking process while planning her project. This implies her sensitivity towards the ethical considerations in her study. It is important that such intellectual engagements should be part of teaching and learning of narrative inquiry. The beauty of narrative inquiry is its nature to capture tacit knowledge of the complexity, uncertainty, ambiguity and dynamism in the human experience.

Ethical considerations in the field of narrative inquiry generally depend on those of qualitative approaches in the interpretive paradigm. However due to its emergent and inclusive nature and the recent trend of employing multimedia approach, and the digital storytelling, participants' vulnerability is likely to become a gigantic issue. We therefore, felt it important to discuss various aspects of research ethics in the interpretive studies in general and those in narrative inquiry in particular.

The experience of Khan from Pakistan showed that some of the concepts in the ethical bedrock seem to be interpreted differently in in Pakistan as those of in the USA. He, for example, wrote in his journal:

The term 'privacy' is a relative term nested in the backdrop of cultural norms and values. For instance, my experiences show that interviewing research participants of the opposite sex in a separate room had always been challenging in Pakistan due to cultural implications. For instance, a female research participant generally cannot sit with a male researcher in a separate room for interviews. Therefore, in my earlier projects I always interviewed female research participants in a semi-public places such as library or a common room while keeping in mind that we both should be visible to others at the same time taking care that our voices should not have been audible to the rest. Whereas, this is not an issue in the USA context. Similarly, as for as the written consent is concerned, in a general Pakistani culture, there is a trend of oral consents. People generally fear and resist to sign a written consent document. In such a situation, it becomes challenging for a researcher when there is an obligation from the sponsors or universities to produce evidences of written consents.

Thus, we discussed all other facets of the ethical challenges that emerge throughout the process from theoretically framing the study, data collection and analyses through interpretation and reporting.

Based on the classroom discourses, we realized that though there are certain global research ethics nested in the individual rights and human dignity, yet particular ethical considerations are contextually specific. Our classroom discussions and reflection showed that cultural norms and values, levels of awareness, information or education, and the how much common people know about research and value it in a society are some of the key factors which can impact the ethical concerns in narrative studies. We realized that certain research studies can be sensitive for some societies and may not for others. Similarly, some state 
and governmental policies can also impact the research ethics. The onus of addressing the ethical concerns is on the researcher always. The researcher needs to be sensitive, to people, places, and cultural concerns during planning, data collection, analysis, reporting, and subsequent publications (Faulkner, 2015).

\section{Narratives of the Narrative Assignments}

Certain findings emerged based on the analysis of the students' various assignments as well as their final project during the instruction phase. We had several questions in mind for the analysis. The first question was, "what influences our students' in their selection of narrative topics for their individual projects?" Our analysis of the individual projects showed that certain elements from their own background that influenced their decision to select research themes. The following were key elements that we identified.

\section{- $\quad$ Personal life experience \\ - Critical incidents \\ - $\quad$ Pursuit of professional development}

From the analysis of students' work, their personal life experience surfaced as the most common element affecting the topic selection for their individual projects. For instance, three of the students, being international, tried to capture the international students or teachers' cross cultural experiences. They focused on how international university students story their cross-cultural learning experience in the United States or vice versa. Similarly, critical incidents from personal and professional lives also seem to influence students' project selection. In one student's case, a critical incident that took place in a cross-cultural seminar, caught her attention. In the seminar, she listened to a story of an international teacher as a non-native speaker, whose day-to-day communications had created misconceptions. The student then, conducted her narrative project to follow up how international teachers experience their lives being non-native speakers in the USA. Likewise, another student had been working as a teacher in an adult education project in the USA. She considered it as a greater learning opportunity to explore the implementation of a particular legislation, Workforce Innovation and Opportunity Act (WIOA) of 2014. She wanted to understand the policy implications for adults in English for Speakers of Other Languages (ESOL) vocational programs.

The second question that guided our analysis of the students' projects was "what were the facilitating factors for the students to accomplish their projects?" We found that beside the encouraging a reflective stance, responding to the guiding questions on the Moodle seem to sharpen thinking of the students towards their projects. Those questions were related to background and research questions of their studies, theoretical and methodological concerns, and ethical considerations. Thus, working on such smaller assignments and building incrementally, helped our students to complete their larger respective projects. 
The third question was related to challenges or difficulties our students faced during the accomplishment of their individual reports. Analysis showed that the students faced two types of problems. One of the problems was related to conceptualizing their respective projects and the second was about narrowing down the focus. Conceptualizing the project was a key challenge for students. The struggle to select their project was a phase that needed much reflection, reading, and synthesis in order to conceptualize it. As discussed earlier, individual reflections and revisiting the past helped them to find a relevant topic for the projects. Similarly, after their topic selection, narrowing down topics towards a doable or achievable task was another challenge for students. Almost all of them came up with some broad themes in the initial phase. Our role as teachers was to enable the students to identify topics, conceptualize and narrow them down. During that period, we face a dilemma. We were worried that asking too many questions would make our students feel that their selection of topic was not worthwhile, and thus they could feel stuck and disheartened. Our dilemma consisted of deciding what to ask, how to ask, and how much to ask. Therefore, we had to be careful in providing feedback. We assured them that our questions were to help them narrow down their studies and to polish their thoughts, not a judgement.

\section{Discussion: What We Learnt From Our Experiences}

University faculty members can learn from their dialogical and collaborative work. The collegial professional relationship not only becomes instrumental for their own learning as professionals but also for the institutional growth (Little, 1990). The collaborative work to develop and team teach opened up insights for us in the context of teaching and conducting research. Our individual strengths and backgrounds became instrumental for designing and instructing a robust and relevant course.

The plan to use narrative approach to study our own experience of teaching narrative inquiry was not only instrumental to our own learning as teachers and researchers but to that of our students. Engaging our students in practice-based learning of narrative inquiry and encouraging them to share their narratives of learning in the class was a robust, but challenging task. As educators and researchers this approach can help us to reflect on the areas of improvement in our teaching and to identify students' misconceptions about narrative inquiry and to zeroing on them so as to facilitate their learning (Cochran-Smith, 2005).

Based on our reflections, we categorize three types of challenges in teaching narrative inquiry in a graduate classroom. The first type of challenge is related to the philosophical underpinnings. For example, the debate on subjective versus objective analysis, which seemed to stem up on the bedrock of students' earlier exposure to more positivist research approaches and analysis, which is, infect, more common in research on education. The second type is related to morality and ethics in doing narrative research studies. It surfaced from the readings, field practices, and classroom discourses that narrative researchers need to be sensitive towards the vulnerability of the research participants, the trustworthiness of the research 
findings through robust procedures of data collection and analysis and being sensitive towards one's own biases (Denzin, 1989).

Similarly, the third category concerns implementation of narrative inquiry within teaching. Teaching is always a complex and challenging task. However, teaching of narrative inquiry through taking a practice-oriented approach, constitutes a process of moving to-and-fro. It always requires time for conceptualizing theories and putting them into practice. Therefore, our session plans were dynamically changing during the entire instructional phase. We changed our sessions based on the reflections on our teaching (Schön, 1983). As mentioned by Biggs and Tang (2011) our purpose of engaging our students in the intellectual debate and practice was twofold. One was 'generic' so as to facilitate their creativity in doing and conducting narrative inquiries. And the other was 'embedded', that is, to foster the abilities in our students to handle and address context-specific issues and challenges while conducting narrative inquiries in their respective fields.

Certain implications for teaching and learning as well as for conducting narrative inquiry surfaced from the analysis of our experience of teaching narrative inquiry. Faculty members' collaboration in teaching and research plays a pivotal role to learn from each other, to identify their weaknesses and address them, and to bring diversity in the university classrooms. Evidence of such practices are commonly seen in the USA, however universities in Pakistan could consider fostering such collaboration. Engaging experienced and novice faculty members in a mentoring process, can result in a productive learning opportunity for both individuals. Many ethical concerns are context-specific. Approaches related to consent, entry negotiations, and confidentiality tend to vary from one context to another. Narrative researchers, therefore need to be vigilant and responsive to context-specific concerns and address them accordingly. Our reflection on time constraints revealed a tension between providing a guided writing practice for narrative reporting in the classroom.

Narrative inquiry is relatively new in the educational research in certain parts of the world, this needs to be encouraged in course on educational research methods. In other words, narratives have a strong space in teaching and learning. Therefore, curricula of teacher education programs should give room to narrative studies; whereby encouraging faculty and prospective teacher in narrative inquiries in the classrooms or elsewhere. Our collaboration helped us to include literature from other parts of the world, that resulted in fruitful discussions in the classroom. It also provided opportunities to discuss narrative based on various theoretical lenses. The more such debates and studies in the classroom the better understanding of the narrative inquiry in different contexts. 


\section{References}

Andrew M., Squire, C., \& Tamboukou, M. (2013). Doing narrative research (2nd Edition). Los Angeles: Sage Publications.

Barkhuizen, G., Benson, P., \& Chik, A. (2014). Narrative inquiry in language teaching and learning research (Second Language Acquisition Research Series) (1st Edition). New York: Routledge.

Bashiruddin, A. (2006). A Pakistani teacher educator's self-study of teaching selfstudy research. Studying Teacher Education, 2 (2), 201-112.

Biggs, J., \& Tang, C. (2011). Quality learning at university: what the student does. New York: The Society of Research into Higher Education \& Open University Press.

Cochran-Smith, M. (2005). The educators as researchers: Multiple perspectives. Teaching and Teacher Education. 21 (2), 219 - 225.

Cole, A., \& Knowles, J. G. (2001). Lives in context: The art of life history research. London: Altamira Press.

Connelly, M., \& Clandinin, D. J. (1990). Stories of experience and narrative inquiry. Educational Researcher. 19 (5), 2 -14.

Connelly, F. M. and Clandinin, D. J., (2006). Narrative inquiry. In Green, J., Camilli, G. and Elmore, P (eds.), Handbook of complementary methods in education research. pp 375-385. Mahwah, NJ: Lawrence Erlbaum.

Denzin, N. K. (1989). Interpretive biography. London: Sage Publications Inc.

Dornyei, Z. (2007). Research methods in applied linguistics. New York: Oxford University Press.

Faulkner, C. (2015). Women's experiences of principalship in two South African high schools in multiply deprived rural areas: A life history approach. Educational Management Administration and Leadership, 43(3), 418 - 432.

Goodson, I. F. (2003). Professional knowledge, professional lives: Studies in education and change. Philadelphia: Open University Press.

Khan, H. K. (2009). Becoming a teacher educator in public sector institutions in Pakistan: stories from personal and professional lives. Unpublished Doctoral Dissertation submitted to the Aga Khan University, Institute for Educational Development, Karachi, Pakistan.

Khan, H. K. (2011). Becoming teacher educators in Pakistan: Voices from the Government Colleges of Education. Journal of Education for Teaching, 37 (3), $325-335$.

Lincoln, Y. S., \& Guba, E. G. (1985). Naturalistic inquiry. London: Sage Publications.

Little, J., W. (1990). The persistence of privacy: Autonomy and initiative in teachers' professional relations. Teachers College Record, 91(4), 509 - 536.

Loughran, J. (2005). Researching teaching about teaching: Self-study of teacher education practices. Studying Teacher Education, 1(1), 5 - 16.

Malik, A.B. (2004). The champions of change: The institutional development and the change management in education sector - The role of teacher. Islamabad: Pangrahics. 
Murray, J. (2005). Readdressing the perspectives: New teacher educators and induction into higher education. European Journal of Teacher Education 28: $67-85$.

Phoenix, A. (2013). Analyzing narrative contexts. In M. Andrews, C. Squire, \& M. Tamboukou (Eds.). Doing narrative research (2nd Edition). Los Angeles: Sage Publications. (pp. 73 - 87)

Schön, D. (1983). The reflective practitioner: how professionals think in action. London: Temple Smith.

Schulte, A. (2005). Assuming my transformation: Transforming my assumptions. Studying Teacher Education, 1 (1), 31 - 42.

Zeichner, K. (2005). Becoming a teacher educator: A personal perspective. Teaching and Teacher Education [Special Issue], 117 - 124. 